NBSIR 86-3400

\begin{tabular}{l} 
Development of Piezoelectric \\
Polymer Gauges for Measuring \\
Pressure on Intaglio Printing Press \\
\hline
\end{tabular}

Steven C. Roth

U.S. DEPARTMENT OF COMMERCE

National Bureau of Standards

Institute for Materials Science and Engineering

Polymers Division

Gaithersburg, MD 20899

August 1986

Prepared for:

Bureau of Engraving and Printing U.S. Department of the Treasury Washington, DC 20461 
NBSIR 86-3400

DEVELOPMENT OF PIEZOELECTRIC

POLYMER GAUGES FOR MEASURING

PRESSURE ON INTAGLIO PRINTING PRESS

Steven C. Roth

U.S. DEPARTMENT OF COMMERCE

National Bureau of Standards

Institute for Materials Science and Engineering

Polymers Division

Gaithersburg, MD 20899

August 1986

Prepared for:

Bureau of Engraving and Printing

U.S. Department of the Treasury

Washington, DC 20461

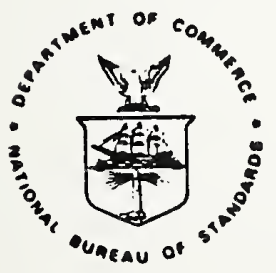

U.S. DEPARTMENT OF COMMERCE, Malcoim Baldrige, Secretary NATIONAL BUREAU OF STANDARDS, Ernest Ambler, Director 


\section{Development of Plezoelectric Polymer Gauges for Measuring}

Pressure on Intagl10 Printing Press

Steven Roth

National Bureau of Standards

Galthersburg, MD 20899

Various phases of the development of a thin polymer film pressure gauge are described. The gauges were used to measure the nip pressure on an intaglio printing press. Pressure sensitive gauges were constructed using plezoelectric poly(vinylidene fluoride) film. Thickness of the gauges ranged between approximately .001n and .003n (30 to 75 micrometers). Pressure sensitivity of a typical gauge was on the order of $10 \mathrm{pC} / \mathrm{ps} 1$. Test results from measurements made on a sheet fed intaglio printing press are given, showing pressure pulses up to almost 46,000 psi and pulse widths around $16 \mathrm{~ms}$. The gauges were generally well behaved mechanically, showing little deterioration over the course of the test. 

U.S. Department of Commerce National Bureau of Standards Center for Materials Sclence

Gaithersburg, MD 20899

Interagency Report to Bureau of Engraving and Printing

"Development of Piezoelectric Polymer Gauges for Measuring Pressure on Intaglio Printing Press"

Steven C. Roth

January, 1985 

Development of Piezoelectric Polymer Gauges for Measuring Pressure on Intaglio Printing Press

\section{Introduction}

In the intaglio process of printing, ink is transferred from recesses in an engraved plate to the printing substrate. To ensure high quality prints, high pressure is exerted on the substrate by an impression roller which deforms sufficiently to force the substrate into contact with the ink. The deforming part of the roller is frequently provided by layers of compressible paper wrapped around a steel drum and held in place by a rubber fabric draw sheet. These parts of an intaglio printing press are shown schematically in Figure 1. Although pressure must be exerted on the substrate, the application of pressure beyond that required for efficient transfer of ink places undue stress on other parts of the press, causes excessive wear on the layers of paper on the impression roller, and can even damage the printing substrate. Also, pressure changes over an extended period of operation due to gradual permanent compression of the paper on the impression roller resulting in corresponding changes in the width of the nip or area over which the force is applied. It would be highly desirable to be able to measure the pressure required for satisfactory printing and then control the parameters of press operation so as not to exceed that pressure. Plezoelectric activity from a thin flexible film of poly(vinylidene fluoride) was first reported in $1969^{(1)}$. Since then, there have been many investigations concerned with the mechanism responsible for plezoelectricity in this organic polymer $(2-4)$ as well as several reports of applications for polymeric transducers $(5-6)$. Previous work sponsored by the Bureau of 
Engraving and Printing at the National Bureau of Standards has shown the Peasibility of measuring nip pressures on the intaglio press using transducers made from thin films of this tough but flexible polymer( 7 ).

The early results showed not only that it was feasible to use the polym meric transducers on the intaglio press, but also revealed many design features to be considered and several problems to be addressed to improve measurements. To prevent destruction of the gauge, it was necessary to place it inside the rubber fabric draw sheet on the impression roiler. To minimize the influence of the movements of the rigging, the gauge was glued to the steel cylinder underneath the rigging with a thin layer of rubber cement. A polymer gauge constructed by cementing together two 25 um - thick flims left unacceptable marks on the printed substrate even though it was "burled" under the rigging. Using 12 um thick film resulted in gauges thin enough not to leave marks on the printed substrate. The polymer film containing the piezoelectrically active area should not extend far beyond the active area in order to minimize stresses transferred to the gauge from inactive parts of the film when they enter the nip. Aluminum electrodes and leads were found to be easily damaged when the polymer was deformed under pressure. The telemetering system used in the early experiments was sufficient to Indicate that a signal was generated by the polymer when subjected to the pressure in the nip but accurate measurements were not possible. Since the polymer gauges also respond to temperature changes (pyroelectric response), it is necessary to know if the polymer is subjected to adiabatic heating during pressurization. 
In the most recent phase of the program to measure pressure on the intaglio press with polymer transducers, many of the earlier problems have been addressed and solved, a telemetry system has been assembled and used, temperature-measuring capability has been added and an additional run on the press has been completed.

Construction of the Gauges

Previous work showed that gauges made from two layers of $25 \mu \mathrm{m}$ polymer film were too thick. Even when burled under the rigging on the impression cylinder, the edge of these gauges showed up as a line on the printed sheet. Consequently, all subsequent gauges were made from 2 layers of $12 \mu \mathrm{m}$ thick sheets of polyvinylidene fluoride. 1

The first step in the production of the gauges involved the deposition of electrodes by vacuum evaporation of metal through an appropriate set of masks. The masks were made from plates of $1 / 16^{n}$ thick aluminum. All metalization was done in a vacuum evaporation deposition system with resistive heating elements. Each set of gauges required thirteen separate evaporation cycles. The masks used produce a set of eight gauges which are eventually cut apart. The deposited electrodes are needed for two purposes: they are used during the poling process, and they serve as electrical leads and electrical shielding in the completed gauge.

The second step in the construction of the gauges 1s poling. The polIng process is the procedure by which the desired portion of the polymer film is made piezoelectrically active. Electrical connection is made to the evaporated leads on opposite sides of the area of film which is to be poled. A high voltage power supply is used to produce an electric field of approxi-

\footnotetext{
The completed gauges were approximately $1 / 2$ " wide and 36 " long with a pressure sensitive active area located near the center.
} 
mately $1 \mathrm{MV} / \mathrm{cm}$ ( 1200 volts applied across the 12 w thick polymer f1lm). The temperature of the film is then raised to $100^{\circ} \mathrm{C}$, allowed to hold for 30 minutes, then cooled back to room temperature. This heating is done by placing the film between two insulating plates of tefion and heating in a small laminating press with electrically heated platens. An alternative method of making a portion of film piezoelectric is to apply a field of 2 MV/cm at room temperature, thus eliminating the use of the heated press. It must be noted that any imperfection in the film or, in the case of the heated press method, any dust or grit on the surface, will likely result in electrical breakdown through the film. This effectively destroys that gauge in which the breakdown occurred.

After the active areas are poled, thin (30 gauge) wires are attached to the end of the leads going to the active areas with a small amount of conductive, silver-filled epoxy. Using a very thin layer of flexible epoxy, a second separate sheet of polymer film, with a continuous indium electrode deposited on the outside, is laminated to the first sheet containing the active layers. The eight individual gauges are then cut apart and a continuous indium electrode is deposited on the outside of the sheet which contains the active areas. This gives a bilaminate construction of two sheets of 12 um thick PVDF, with a continuous coating of indium on the outside of each sheet and an electrical evaporated lead running down the center to the active area. The electrical lead in the center of the two sheets, of course, carries the signal which will be developed when the active area is subjected to a pressure change. The indium outer electrodes act as electrical shielding for the complete gauge. 
The final step in construction of the gauges is the addition of a miniature coaxial connector to the end of the gauge. The copper wire leading from the center lead of the gauge is soldered to the center conductor of the coaxlal connector. Electrical connection is made between each outside indium electrode and the shield of the coaxial connector. These connections are then potted with an insulating epoxy for protection.

Embedded Gauges

During the course of this project, considerable effort was made to develop an embedded or encapsulated gauge. Objections were raised that, perhaps, a more accurate representation of the printing pressure would be obtained if the gauge were located closer to the currency being printed rather than being buried under the rigging material. Therefore, it was decided that an attempt would be made to to place a gauge on an engraved plate on the bottom roller.

Three gauges were to be mounted along the forward, leading edge of the engraved plate just in front of the actual engraving. Each gauge was to have both a temperature and a pressure sensitive element. A gauge would be mounted near each outside edge of the plate. The third gauge would be mounted near the middle of the plate.

Because the bottom roller of the printing press is less accessible than the top roller, both physically and from a telemetry standpoint, a different approach to the construction and mounting of the gauges was chosen. We decided to try encapsulating the gauges into the engraved plate during the manufacturing of the plate. Thin (.001" thick) strips of precisely cut tin foll were glued to the alto plate. Two strips were used, one on top of the other, with the top strip being narrower than the bottom. When the engraved 
plate is deposited on the alto the result is to form on the engraved plate a two step channel which was wider on the top. The polymer gauge was to be placed in the narrow bottom portion of the channel while the wider upper part was to be filled with electroplated nlckel. Three tee-shaped gauges were then used. The gauges were approximately 25 um thick with each arm of the tee being 2 inches long and $1 / 8$ inch wide. The stem of the tee was approximately $3 / 8$ inch wide. One arm had a pressure sensitive element, the other a temperature sensitive element (Figure 2). The gauges were to be glued into the bottom of the channel. Then the gauges were to be covered with electrodeposited nickel and ground flush with the rest of the plate. This would produce a gauge that was encapsulated directly into the engraved plate.

The problem which eventually caused us to drop this approach was the difficulty involved in doing the electrodeposition over the gauge. Several different sets of gauges were constructed. Two adhesives were tried: thin layers of rubber cement or flexible epoxy. The rubber cement had the advantage that any excess or overflow could be easily removed. The gauges bonded with the epoxy had to be bonded under pressure to squeeze out as much epoxy as possible. The channel intended for the nickel encapsulating layer became filled with epoxy which then had to laboriously be removed. Thus, rubber cement was easier to use, however, the epoxy produced a better bond.

In order to electroplate over the polymer gauge, a conductive layer had to be used. Both vacuum deposited aluminum and indium were tried, but these did not seem to be compatible with subsequent deposition steps. Finaliy, vacuum deposited nickel was used since this should be most compatible with the subsequent nickel electrodeposition. Nickel was not the first metal 
tried due to the difficulty involved in the vacuum evaporation of nickel

onto the polymer. The heat involved in a nickel vacuum evaporation, using a resistive heated source, tends to distort or melt the thin polymer film.

Several sets of nickel coated, epoxy attached gauges were produced. Various electrodeposition procedures were tried, both in-house at the Bureau of Engraving and Printing and by a private contractor, without success. It was at this point that we decided to abandon this avenue of research.

Temperature Measurement

When a material undergoes a sudden compression, its temperature increases due to adiabatic heating. Since the polymer gauge is sensitive to changes in temperature as well as changes in pressure, to make an accurate pressure measurement the temperature change must be measured independently and compensated for. The constraints on the temperature sensor are the same as for the pressure gauge, that is, very thin and with a response time in milliseconds. Therefore, a thin film evaporated metal thermocouple was used. Using the vacuum evaporation system and a set of masks, a bimetallic thermocouple junction was deposited immediately behind the active area. The thermocouple leads extended along the polymer strip and were terminated at the connector end in much the same fashion as the signal lead from the active area.

An inherent limitation of a vacuum deposition system using resistance heated elements is that only pure metals can be deposited rather than common thermocouple alloys such as constantan or alumel. Bismuth and antimony exhibit large thermal EMF's (approximately $120 \mu \mathrm{V} /{ }^{\circ} \mathrm{C}$ ). But thermocouple gauges made from them did not adhere well to the polymer substrate and were very brittle. Aluminum, indium, and nickel all adhere well to the polymer. 
Subsequent gauges were made using either indlum/aluminum or nfckel/aluminum thermocouples. The disadvantage of using these pairs of metals as thermocouples is their low sensitivity. The nickel/aluminum thermocouples had a sensitivity of approximately $11 \mu \mathrm{V} /{ }^{\circ} \mathrm{C}$ whlle the sensitivity of the indium/aluminum thermocouple was only about $3 \mu \mathrm{V} /{ }^{\circ} \mathrm{C}$.

Subsequent work w1th the evaporated thermocouple gauges showed no detectable signal above the nolse level of the electronics. From this it was concluded that adiabatic heating of the polymer gauge during the pressure pulse does not produce significant error in the pressure measurement. It must be noted that these results may only apply when the gauge is mounted on top of the metal cylinder which would act as a large thermal sink.

Telemetry system

Previous work involved the use of a single channel, frequency modulated (FM) telemetry link. This was adequate to demonstrate that a signal was generated by the pressure gauge. However, due to variations in antenna loading, the transfer function of the link was not known, making it impossible to obtain an accurate value for the nip pressure.

In order to obtain more quantifiable results, a two channel, commercial model, FM telemetry system was purchased. This system utilized an FM carrier signal on both channels. This meant that as long as the recelver was able to lock onto the carrier signal, the gain of the system while in use on the press would be the same as the gain of the system measured in the laboratory. The telemetry system consisted of three basic units. One channel, to be connected to the pressure gauge, contained a charge amplifier and an associated transmitter. The second channel, to be connected to the thermo- 
couple temperature gauge, contained a voltage amplifier with its associated transmitter. We were not able to use the ava1lable, commercial thermocouple amplifier as a voltage amplifier since its frequency response only went up to a few Hertz. Instead a strain gauge amplifier was selected as the voltage amplifier for the thermocouple. As an added complication, due to the low sensitivity of the thin film thermocouples, a preamplifier had to be built and added to the temperature channel. All of these components were battery powered and were housed in a cylindrical container $11 / 4$ inch wide and 8 inches long. The third major component of the system was the receiver. After demodulation the two signals were fed from the receiver into a two channel digital oscilloscope.

\section{Laboratory Measurements}

The laboratory calibration of the gauges can be divided into three areas: (1) piezoelectric response of the poled element, (2) pyroelectric response of the poled area, and (3) temperature sensitivity of the thermocouple element. A plezoelectric constant can be determined by placing the gauge in a pressure cell and measuring the response to a change in hydrostatic pressure. For the measurement to be valid, the rate of change of pressure must be as small as possible to reduce the effect of adiabatic heating. Since the thickness is much less than the length and width, this measurement gives a good approximation of the $d_{33}$ piezoelectric constant. Plezoelectric constant, $d$, is obtained from the following relation:

$$
\mathrm{d}=\frac{1}{\mathrm{~A}} \frac{\Delta \mathrm{Q} / \Delta \mathrm{t}}{\Delta \mathrm{P} / \Delta \mathrm{t}}
$$

where $\Delta Q / \Delta t$ is the rate of charge generation or current, $\Delta P / \Delta t$ is the rate of charge of pressure, and $A$ is the area of the active element. 
In a similar manner, the pyroelectric coefficient, $p$, can be determined from the current generated by a known rate of change of temperature, $T$ :

$$
p=\frac{q}{A Q T / \Delta t} \frac{\Delta T / \Delta t}{0}
$$

Limitations of deriving the pressure and temperature sensitivity of the gauge by the above methods, are that they are lower frequency measurements than expected on the printing press and the pressure levels are low compared to the pressures expected in use.

Primarily due to the low pressure range limitation, an alternative method that comes closer to simulating the conditions the gauge would actually experience was used to measure the pressure sensitivity of the gauges. The pressure sensitive area of the gauge was placed on a flat metal plate. A second, smaller, rectangular metal plate was then placed on top of the gauge. The size of this indenter plate was such that it was larger than the active area and narrower than the width of the complete gauge. A pneumatic ram was used to apply a load to the indenter. The charge developed by the polymer gauge was recorded as a function of the applied load. A representative record is shown in Figure 3.

The sensitivity of the evaporated metal thermocouples was calculated by immersing the gauge in chilled water and comparing the voltage produced with the temperature change, as measured with a reference thermocouple.

\section{Field Measurement}

Mounting of the gauges under the rigging of the impression cylinder was best accomplished by coating both one side of the gauge and the cylinder with a thin layer of diluted rubber cement. The gauge was then placed on the surface of the cylinder in line with the cylinder axis. The bulky 
connector was hung over the edge of the cylinder and taped down in an area free of any actuating or gripping mechanisms. The thin layer of rubber cement was adequate to keep the gauge from shifting under the rigging. To protect the indium outer coating of the gauge from abrasion due to possible motion of the rigging, a very thin layer of teflon tape (thread packing tape) was placed on top of the gauge. Another precaution found to be necessary during the course of the experiment was that the edge of the cardboard rigging, from which the gauge emerged, had to be rounded and smoothed to prevent 1t cutting into the gauge.

Production restraints on the use of the press resulted in only one experimental run using the two channel telemetry system. The signal obtalned from the polymer pressure gauge was repetitive and regular. Several recordings were made. However, on later analysis it was found that the signal represented a severely clipped waveform. An analysis of the circult used in the FM telemetry system showed that although the charge amplifier front end was capable of handling a charge equivalent to several thousand ps1 the FM transmitter was not able to take the full output of the charge amplifier without overloading.

Subsequent work was done to instrument a web-fed intaglio press at the Bank of Denmark and a sheet-fed press at the Bank of England. The results of the experiment conducted on the sheet-fed press are given in Appendix A. 


\section{Appendix A}

Data Obtained From Sheet-Fed Intagl1o Press at Bank of England, London

Measurements were made during the week or May 21,1984 on a sheet-fed intaglio press. The gauges used were developed for a web-fed press at the Bank of Denmark and were similar in design to those discussed previously, with the following differences. First, no evaporated thermocouple temperature sensor was included, since it was decided that the sensitivity of the resulting temperature gauge was so low that the signal would be buried in the electrical noise. Second, since on the web-fed press the gauges experienced surface abrasion which rubbed off the indium coating, a protective film was applied to both sides of the completed gauge. A layer of 12: $\mu$ m thick polymer film was laminated on each side of the gauge with flexible epoxy. The two additional layers of plastic and the two additional epoxy layers increased the total thickness of the completed gauge to almost $75 . \mu \mathrm{m}\left(.003^{\prime \prime}\right)$. Although the resulting gauge was more durable, the increased thickness makes it unacceptable for actual production runs and was used for experimental purposes only.

For the experimental runs, no paper was fed through the press. Also, no ink was used and the cylinders were not heated. The rigging used had been installed previously and had been run-in. The gauges were attached directly on to the surface of the engraved plate, in the flat spaces between the rows of engraved notes. A transfer adhesive was used to bond the polymer pressure gauge to the engraved plate. 
A major change was made in the telemetry system used to transmit the signals across the rotating-stationary 1nterface. Sealed, mercury wetted slip rings were mounted on the end of the cylinder axis. A battery powered four channel charge amplifler was mounted on one face of the cylinder with the output wires leading to the slip-ring.

Experimentally, the press was set-up to vary both speed and load. Three rotational rates $(2000,4000,6000$ sheets/hour) were used at each of four load settings. The load applied was measured by a Giorgi gauge. Starting at the lowest load setting, the press was brought up to speed. The output of one of the three gauges which had been glued to the engraved plate was fed into a digital, processing oscilloscope. A group of successive pulses (usually nine) were captured and stored in the oscilloscope. An average was computed for the group of pressure pulses and stored on a digital tape recorder for later analysis.

A typical pulse average is shown in Figure 4, giving the time history of the applied pressure. Table 1 lists the peak height of the pulse and the time between half peak points for three different operating speeds and four interference levels. The corresponding readings from the Giorgi gauge for each interference level are also given.

$$
\begin{aligned}
& P=V_{\text {out }}{ }^{*} C_{v} \\
& P=\text { calculated pressure } \\
& \text { where } C_{v}=1 / G * P_{s} \\
& V_{\text {out }}=\text { output of charge amplifier } \\
& G=\text { gain of charge amplifier } \\
& P_{S}=\text { sensitivity of gage }
\end{aligned}
$$




\section{References}

1. H. Kawai, Jpn. J. Appl. Phys. 1 , 975 (1969).

2. R. Hayakawa and Y. Wada, Advances in Polymer Science, Vol. XI (Springer, Berlin, Heidelberg, New York 1973) p. 1.

3. M. G. Broadhurst, G. T. Davis, J. E. McKinney, and R. E. Collins, J. Appl. Phys. 49, 4992 (1978).

4. M. G. Broadhurst and G. T. Davis, Ferroelectrics, 60, 3 (1984).

5. M. G. Broadhurst, S. Edelman, and G. T. Davis, Org. Coat. \& Plastics, Chem. 42, 241 (1980). [ACS Meeting; Houston, TX, March 23-28, 1980].

6. M. A. Marcus, Ferroelectrics, 40, 29 (1982). 
(1) 
Table 1a - Gauge 24

Sheet Speed

(sheets/hr)

\section{Gior1 Gauge \\ (tons)}

$\begin{array}{cc}2000 & 9 \\ & 16.2 \\ & 34.2 \\ & 52.2 \\ 4000 & 9 \\ & 16.2 \\ & 34.2 \\ & 52.2 \\ & 9 \\ & 9000 \\ & 16.2 \\ & 34.2 \\ & 52.2\end{array}$

\section{Polymer Gauge}

(psi)

4881

6660

11340

14390

4369

6768

11390

14270

5168

6871

11360

15910
Pulse Width

(ms)

28.5

26

23.4

23.4

14.1

12.1

12.5

9.6

9.4

7.9

8.6 
Table ib - Gauge 25

Sheet Speed

(sheets/hr)

2000

4000

6000

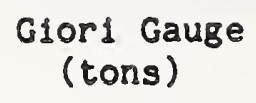

9

16.2

34.2

52.2

9

16.2

34.2

52.2

9

16.2

34.2

52.2
Polymer Gauge (ps1)

17160

21460

29080

34450

16200

21590

26220

39990

21690

26210

33390

38040
Pulse Width

(ms)
34.8

39.4

46.1

48.4

17.2

23.2

24.8

16.0 
Table 1c - Gauge 26

Sheet Speed

(sheets/hr)

2000

4000

6000

\section{Giorl Gauge \\ (tons)}
Polymer Gauge
(ps1)

2851

6224

17020

41970

52.2

9

16.2

34.2

52.2

9

16.2

34.2

52.2
2698

5138

14500

39890

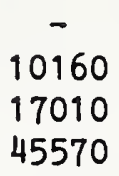

Pulse Width

(ms)

40.6

41.0

41.4

49.6

15.4

18.2

19.3

24.6

11.7

19.7

13.8

16.4 


\section{REPRESENTATION OF CYLINDERS OF SHEET-FED INTAGLIO PRESS AND PLACEMENT OF POLYMER GAUGES}

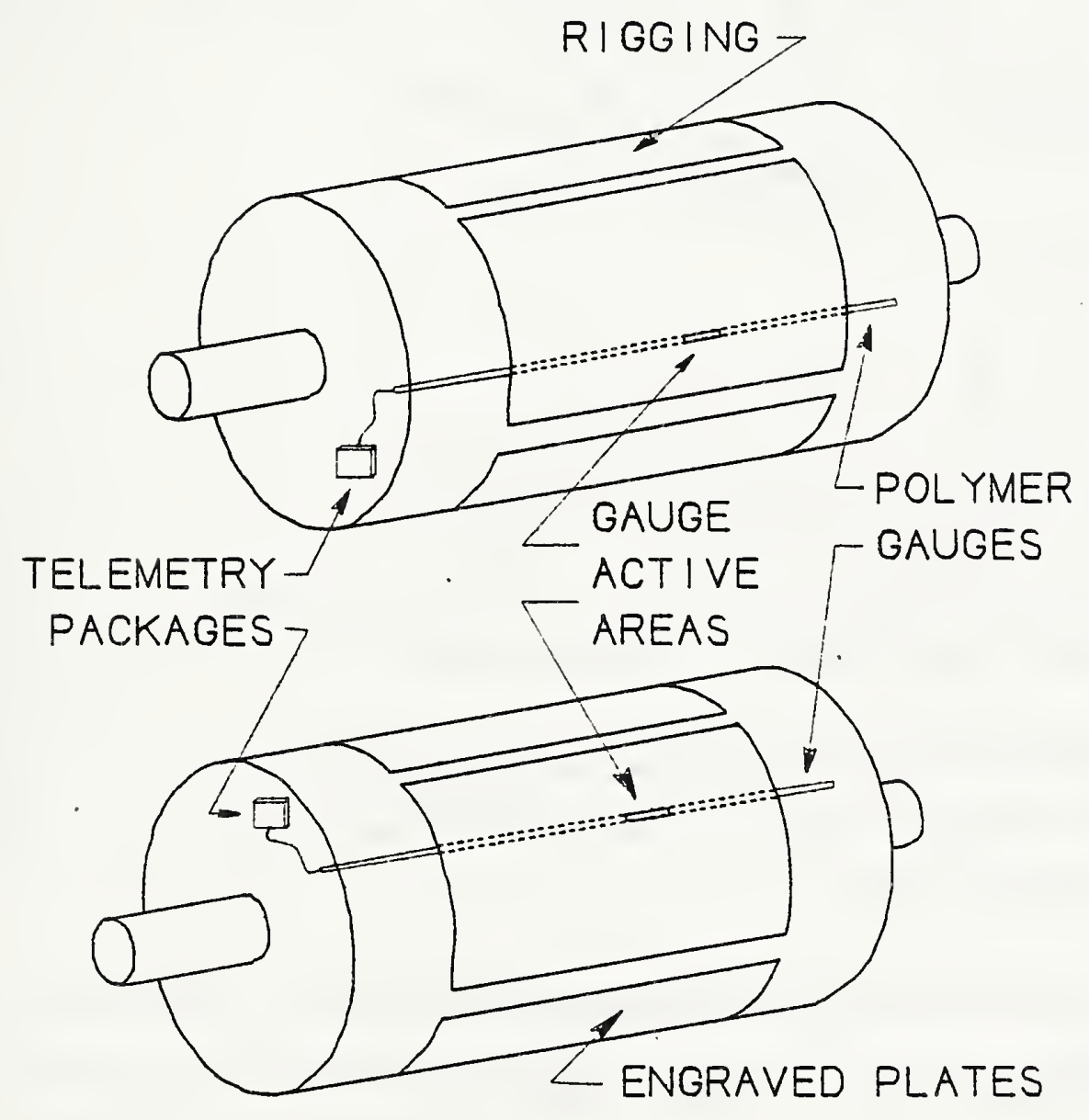

F I GURE 1 
Engraved Plate

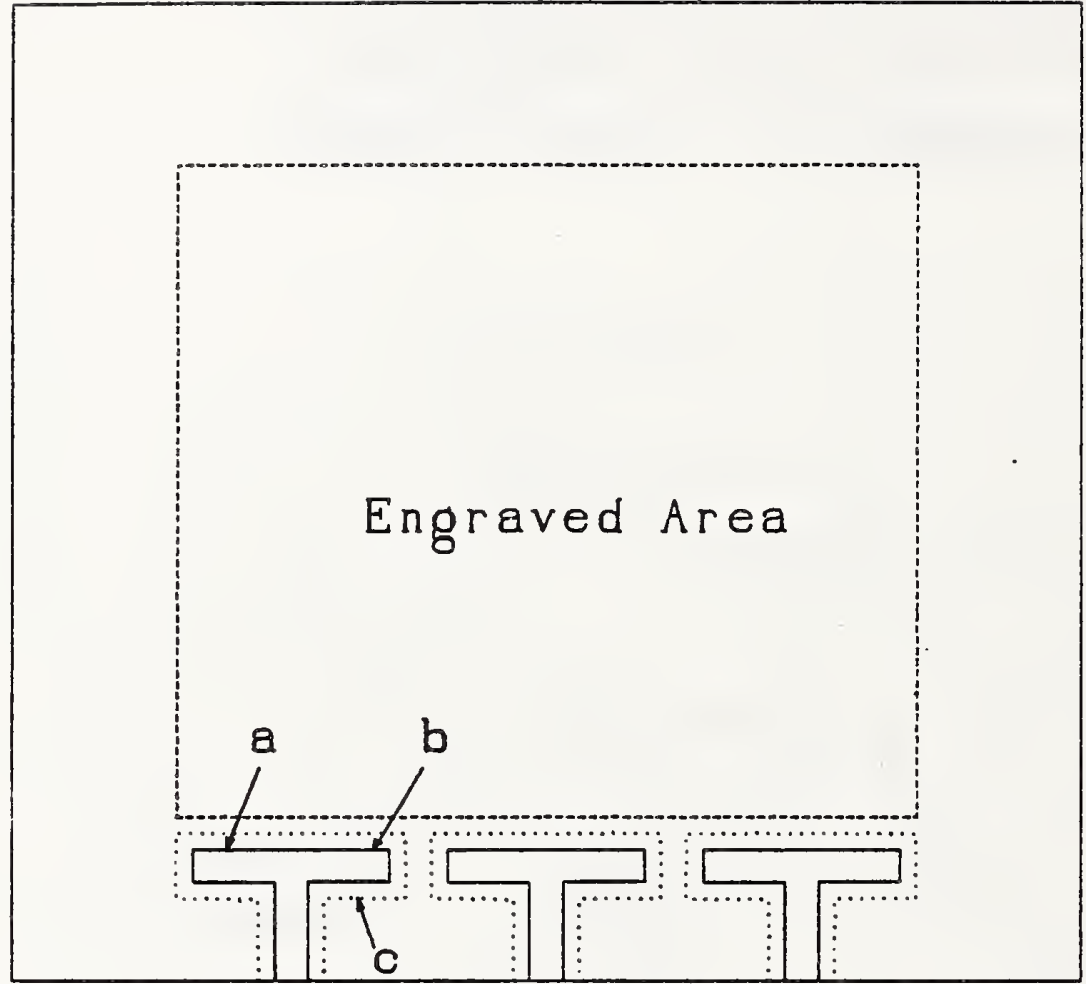

Leading Edge of Engraved Plate

Representotion of engraved plote (without engroulng). showing plocement of polyner gouges prlor to encopsulation by overploting with o thin nickel loyer.

a) pressure sensitive element of polymer gouge

b) temperature sensitive el ement of gouge

c) $0.001^{\circ}$ deep channel of area to be fllled in with electroploted nickel

FIGURE 2 


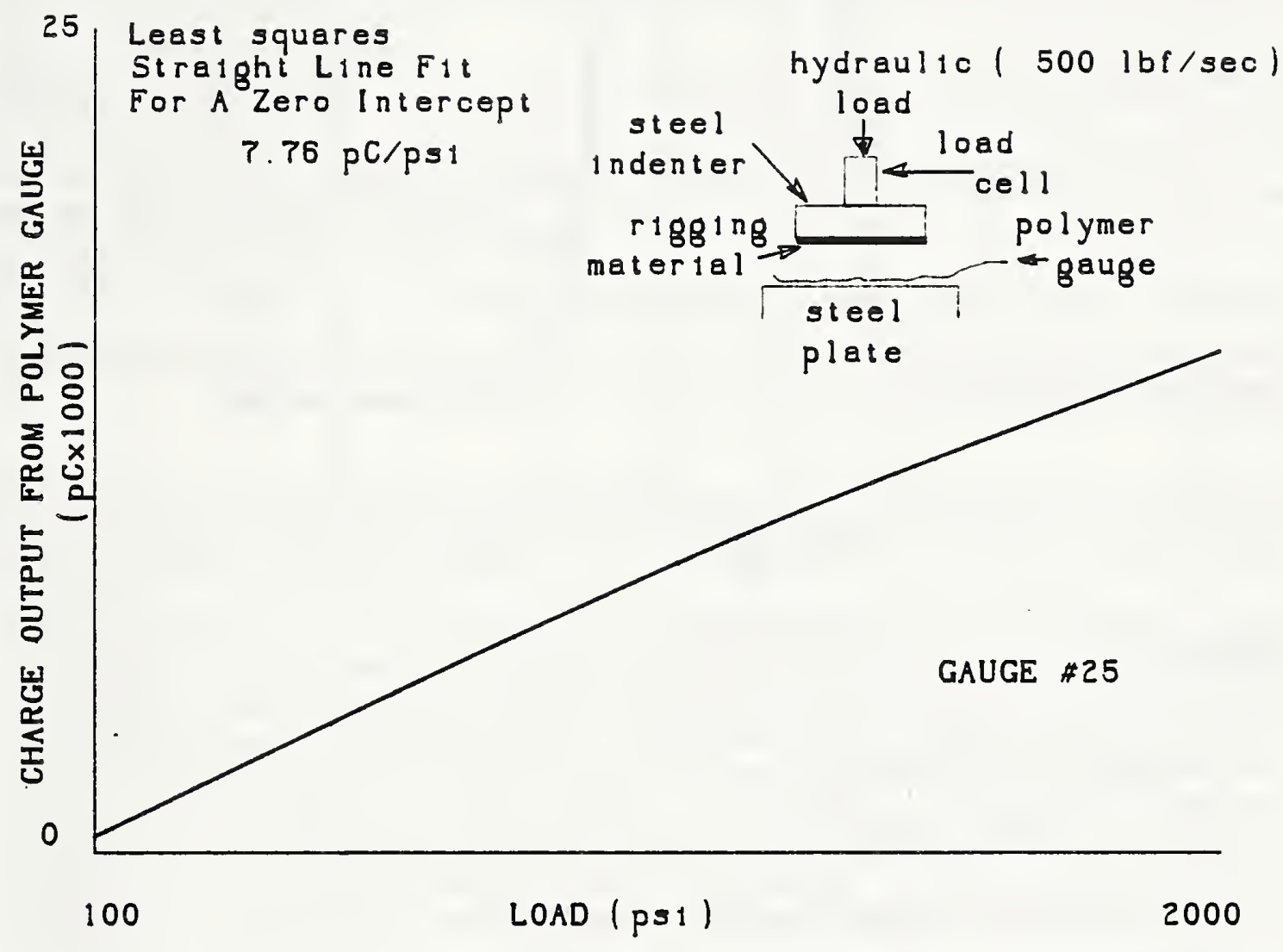

LABORATORY CALIBRATION OF POLYMER GAUGE.

DEVIATION OF RESPONSE FROM A STRAIGHT LINE FIT WAS

TYPICALLY LESS THAN $1 \%$.

FI GURE 3 


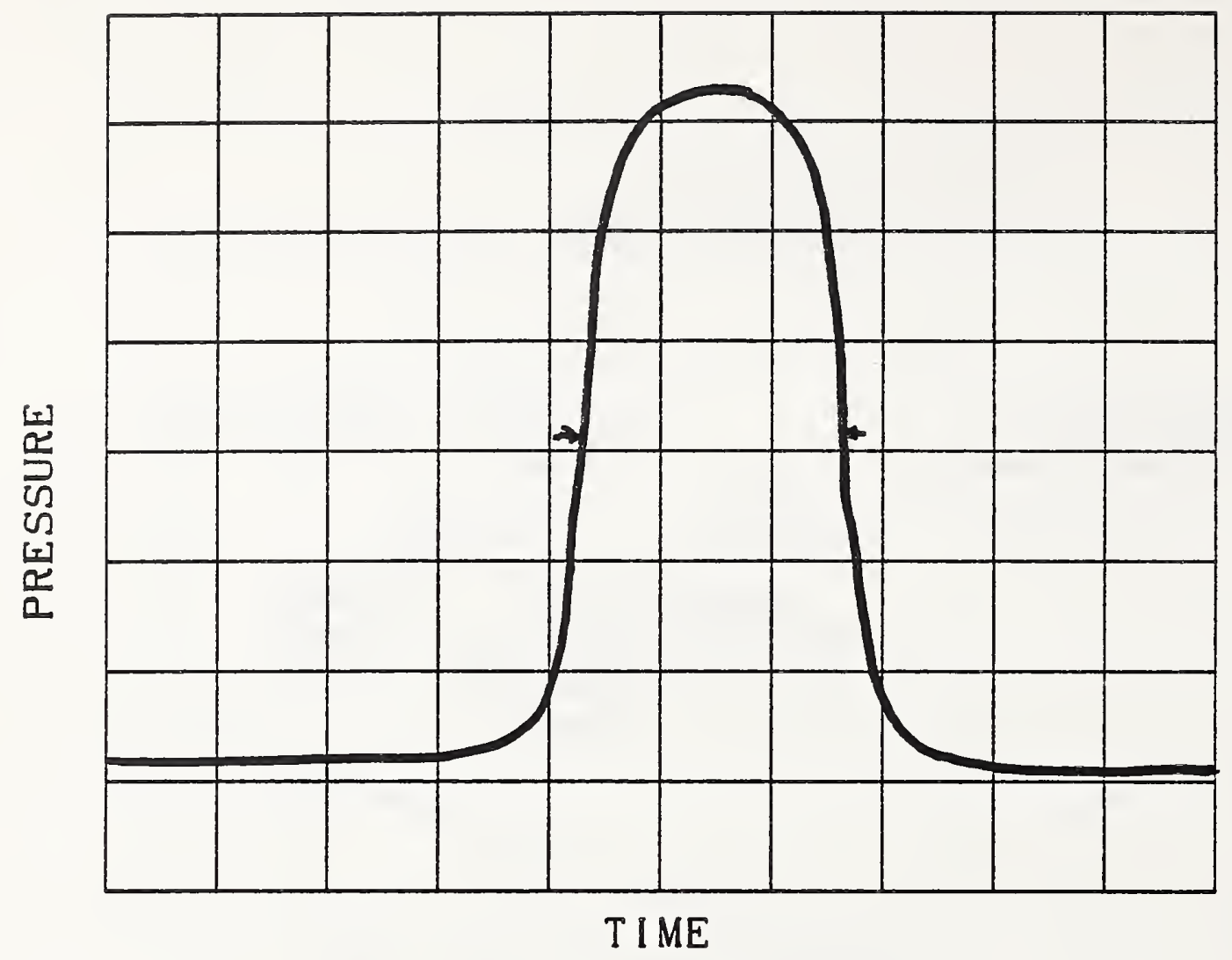

GAUGE \#25

4000 SHEETS/HOUR

34.2 TONS LOAD

10 MS/DIV HORIZONTAL SCALE

$5000 \mathrm{PSI} / \mathrm{DIV}$ VERTICAL SCALE

24.6 MS BETWEEN CURSORS LOCATED AT $P(\max ) / 2$ 33890 PSI PEAK AMPLITUDE

TYPICAL AVERAGE OF SUCCESSIVE PRESSURE PULSES

F I GURE 4 
BS-IIUA IREV. Z AC)

U.8. DEPT. OF COMA.

TrELIOGRAPHIC DATA

SHEET (See Instructions)

1. PUBLICATION OR REPORT NO.

NBSIR $86-3400$

2. Performing Orzan. Report Nof 3. Publication bate

OCTOBER 1986

4. TITLE AND SUBTITLE

Development of Piezoelectric Polymer Gauges for Measuring Pressure on Intaglio Printing Press

5. AUTHOR(S)

S. C. Roth

\begin{tabular}{l|l}
\hline 6. PERFORMING ORGANIZATION (If jolnt or other than NBS, see instructions) & 7. ContracU Grant No.
\end{tabular}

NATIONAL BUREAU OF STANDARDS

DEPARTMENT OF COMMERCE

WASHINGTON, D.C. 20234

8. Type of Report \& Period Covered

9. SPONSORING ORGANIZATION NAME AND COMPLETE ADORESS (Street, City, Stote, ZIP)

Bureau of Engraving and Printing

U. S. Department of the Treasury

Washington, DC 20461

10. SUPPLEMENTARY NOTES

Document describes a computer program: SF-185. FIPS Software Summary, is attached.

11. ABSTRACT (A 200-word or less factual summary of most significant information. If tocument includes a significant bibliogrophy or literoture survey, mention it here)

Various phases of the development of a thin polymer film pressure gage are described. The gages were used to measure the nip pressure on an intaglio printing press. Pressure sensitive gages were constructed using piezoelectric poly(vinylidene fluoride) film. Thickness of the gages ranged between approximately .001" and .003" (30 to 75 micrometers). Pressure sensitivity of a typical gage was on the order of $10 \mathrm{pC} / \mathrm{psi}$. Test results from measurements made on a sheet fed intaglio printing press are given, showing pressure pulses up to almost $46,000 \mathrm{psi}$ and pulse widths around $16 \mathrm{~ms}$. The gages were generally well behaved mechanically, showing little deterioration over the course of the test.

12. KEY WORDS (Six to twelve entries: olphobetical order: capitalize only proper names; and separate key words by semicolons) Intaglio printing; piezoelectric polymer; polyvinylidene fluoride; thin film pressure gage; transducer

\section{AVAILABILITY}

Unlimited

X For Official DIstribution. Do Not Release to NTIS

$\square$ Order From Superintendent of Documents, U.S. Government Printing Office, Washington, D.C. 20402.

14. NO. OF

PRINTED PAGES

Order From National Technical Information Service (NTIS), Springfield, VA. 22161

15. Price 
$-$ 